\title{
Stereotyped personality trait ratings of concrete and "typical" stimulus persons
}

\author{
JERRY N. CONOVER, GEORGE EDW. SEYMOUR, MELVIN H. MARX \\ and MONICA M. MOORE \\ University of Missouri, Columbia, Missouri 65201
}

\begin{abstract}
Male and female subjects provided ratings of personality traits for students pictured in a large set of facial photographs. Each photograph was rated on each of eight traits. Trait ratings were also provided for subjects' impressions of "typical" male and female college students. Male and female subjects did not differ in their ratings of photographs or of typical students. Sex of the picture (and of the typical student) did reliably influence the ratings for several traits. Certain groups of traits appeared to form intercorrelated clusters, suggesting the operation of a halo effect.
\end{abstract}

A person's appearance is generally thought to influence the impression formed of him or her by others (Stone, 1962). People readily attribute various personal characteristics on the basis of physical features when other, more relevant, information is unavailable. Dion, Berscheid, and Walster (1972) reported that individuals have stereotyped notions of personality traits that correspond to different levels of physical attractiveness. The general conclusion of their investigation was that individuals perceived as attractive tended to be stereotyped with more desirable personality traits. This finding is in accord with the well-known "halo effect": An impression that a person rates highly on a given trait tends to elevate ratings of other traits on which there is little or no information (Thorndike, 1920).

As part of an ongoing research program in our laboratory, we selected a set of personality traits for use in several learning tasks. We had access to a large collection of photographs of college students and wanted to gather data about the frequency with which personality traits would be ascribed to the individuals in those photographs. Since the halo effect results in certain sets of traits commonly being attributed to the same individual, we desired to determine which traits were, in general, least intercorrelated, so that our research efforts could be based on relatively independent trait dimensions.

The present study, therefore, measured college students' ratings of numerous photographs of other students to obtain this trait information. In addition, we asked participants to provide comparable trait

This research was supported in part by Research Career Award 1-K6-MH-22,023 from the National Institute of Mental Health to the third author, and by Grant DAHC19-74-G-0008 from the U.S. Army Research Institute for the Behavioral Sciences. The views expressed herein are those of the authors and do not necessarily reflect the views of the Department of the Army. Reprints may be obtained from Melvin H. Marx, Department of Psychology, University of Missouri-Columbia, 210 McAlester Hall, Columbia, Missouri 65201. ratings of their impressions of the "typical" male and female college students. The latter information permits a comparison of the concrete stimuli represented by the photographs with general, internal schemata representing male and female students.

\section{METHOD}

\section{Subjects}

Thirty-four students enrolled in introductory psychology courses at the University of Missouri-Columbia participated for class credit. Eight or 10 subjects, half females and half males, participated in each of four experimental sessions.

\section{Materials}

Stimuli were head-and-shoulder photographs of college students taken from recent yearbooks of the University of Missouri-Columbia. From a pool of several hundred such portraits, pictures of 56 males and 56 females were randomly selected. The photographs were projected as slides onto a large screen in front of the subjects.

\section{Procedure}

Fifty-six photographs were presented in each session. The first 28 pictures were of female faces for half the sessions and of male faces for the other half; the second 28 pictures were of the opposite sex. Presentation of the pictures was counterbalanced, so that a subset of 28 male pictures was presented with a subset of 28 female pictures during the first session and with the remaining 28 female pictures during the second session. Likewise, the remaining male pictures were presented with each of the above female picture subsets during the third and fourth sessions, respectively.

Participants were instructed to study and assess certain personality characteristics for each face as it was presented. They were informed that there was no way to know what the pictured person's true personality was like, so they would have to make judgments about the traits solely on the basis of the person's appearance. Subjects rated each face on each of the following trait descriptions: emotional, friendly, honest, independent, intelligent, lazy, shy, and sincere. Trait order was varied systematically through eight different random sequences so that each trait was rated first, second, and so on, an equal number of times. Traits were announced from a tape recorder at a rate of $4 \mathrm{sec} /$ trait.

Ratings were specified in terms of how often the subject 
thought the trait descriptions applied to the person in each picture. Ratings ranged from 1 to 6 and were defined to mean, respectively, "never," "rarely," "occasionally," "frequently," "most of the time," and "always." Each subject recorded his or her responses on a sheet of paper with places for eight responses to each picture.

Following presentation of the pictures, subjects were asked to give their impressions of the "typical college male" and the "typical college female" for the same eight traits. (Note that the decision to collect these data was not made until after the first session.)

\section{RESULTS}

Separate multivariate analyses of variance were performed both on ratings of photographs and on ratings of typical students, with sex of the subject and sex of the picture as independent variables. Mean ratings (across 28 pictures) per subject for each of the eight traits served as dependent variables. The slightly conservative $\mathrm{F}$ approximation to the Pillai statistic, recommended by Olson (1976), was used in all multivariate tests. Overall, ratings for photographic stimuli and for typical students were quite similar. Sex of the subject was not a significant factor in any of the trait ratings $[F(8,25)=.57$, for photographs; $F(8,15)=.88$, for typical students], nor was the interaction of subject sex with sex of the picture $[F(8,25)=.90]$ or with sex of the typical student $[F(8,15)=1.92]$. Sex of the picture was significant $[F(8,25)=13.28, p<.0001]$, revealing reliable effects for all traits except "intelligent" and "shy" (see Table 1). The only traits on which male pictures were rated higher than female pictures were "lazy" and "independent." Similarly, sex of the typical student was significant $[F(8,15)=5.70, p<.002]$, with the typical male rated as lazier and more independent than the typical female. On all other traits except "friendly," typical females were rated higher than typical males (see Table 1).

Correlation coefficients were then computed between each pair of traits, separately for pictures of females and of males, disregarding subjects' sex. These correlations are presented in Table 2, which is divided into two parts

Table $\mathbf{i}$

Mean Trait Ratings for Facial Photographs and "Typical" College Students

\begin{tabular}{|c|c|c|c|c|c|c|}
\hline \multirow[b]{3}{*}{ Trait } & \multicolumn{3}{|c|}{ Facial Photographs } & \multicolumn{3}{|c|}{ Typical Students } \\
\hline & \multicolumn{2}{|c|}{ Means } & \multirow[b]{2}{*}{$F(1,32)$} & \multicolumn{2}{|c|}{ Means } & \multirow[b]{2}{*}{$F(1,22)$} \\
\hline & Male & Female & & Male & Female & \\
\hline Emotional & 3.26 & 3.76 & $40.85 \dagger$ & 2.83 & 4.33 & $37.72 \dagger$ \\
\hline Friendly & 3.92 & 4.21 & $23.39 \dagger$ & 4.67 & 4.67 & 0.00 \\
\hline Honest & 3.98 & 4.33 & $38.97 \dagger$ & 4.13 & 4.63 & $7.40^{*}$ \\
\hline Independent & 4.15 & 3.93 & $14.28 \dagger$ & 4.96 & 3.96 & $23.47 \dagger$ \\
\hline Intelligent & 3.92 & 3.90 & .11 & 4.17 & 4.67 & $11.65 * *$ \\
\hline Lazy & 3.13 & 2.91 & $8.68 * *$ & 3.33 & 2.75 & $8.49 * *$ \\
\hline Shy & 3.16 & 3.16 & 0.00 & 2.50 & 3.13 & $9.56 * *$ \\
\hline Sincere & 3.82 & 4.13 & $32.84 \dagger$ & 3.75 & 4.67 & $19.15 \dagger$ \\
\hline
\end{tabular}

Note-Rating scale ranges from 1 (never) to 6 (always).

${ }^{*} p<.05 \quad{ }^{* *} p<.01 \quad$ tp $<.001$
Table 2

Correlations Among Trait Ratings for Facial Photographs

\begin{tabular}{lrrrrrrrr}
\hline \multicolumn{1}{c}{ Trait } & It & F & Sh & L & In & E & Si & H \\
\hline Intelligent (It) & & 33 & -43 & -30 & 28 & -08 & 52 & 42 \\
Friendly (F) & 43 & & -24 & -26 & 29 & -12 & 71 & 73 \\
Shy (Sh) & -16 & -10 & & 34 & -38 & 14 & -16 & -21 \\
Lazy (L) & -19 & -30 & 36 & & -13 & 29 & -19 & -36 \\
Independent (In) & 36 & 25 & -29 & 01 & & -28 & 22 & 10 \\
Emotional (E) & 43 & 36 & 19 & -21 & -02 & & 03 & -06 \\
Sincere (Si) & 30 & 67 & -07 & -13 & 32 & 40 & & 81 \\
Honest (H) & 46 & 66 & -24 & -42 & 17 & 22 & 65 & \\
\hline
\end{tabular}

Note-Correlations are expressed without preceding decimal points. Data for pictures of males appear to the left, and for females to the right, of the main diagonal. To be significant at $p<.05$, correlation coefficients must exceed \pm .33 .

Table 3

Correlations Among Trait Ratings for "Typical" College Students

\begin{tabular}{lrrrcrcrr}
\hline \multicolumn{1}{c}{ Trait } & It & F & Sh & L & In & E & Si & H \\
\hline Intelligent (It) & & 52 & -24 & 00 & -02 & 13 & 04 & 00 \\
Friendly (F) & 03 & & -07 & 18 & 37 & 05 & 15 & 00 \\
Shy (Sh) & -07 & -51 & & 13 & -05 & 18 & 00 & -07 \\
Lazy (L) & -60 & 33 & 24 & & 12 & -07 & 00 & 17 \\
Independent (In) & 18 & -21 & 09 & -22 & & -14 & -03 & 04 \\
Emotional (E) & 10 & -28 & 36 & -03 & -17 & & 15 & -15 \\
Sincere (Si) & 19 & -14 & 09 & -41 & 10 & -17 & & 60 \\
Honest (H) & 31 & 00 & 03 & -25 & 07 & -25 & 57 & \\
\hline
\end{tabular}

Note-Correlations are expressed without preceding decimal points. Data for typical males appear to the left, and for typical females to the right, of the main diagonal. To be significant at $p<.05$, correlation coefficients must exceed \pm .39 .

separated by the main diagonal: The upper right half presents intercorrelations for female pictures and the lower left half presents intercorrelations for male pictures. Each correlation coefficient is based on 34 pairs of scores, each pair representing the mean rating across all 28 pictures of a given sex provided by each subject for that pair of traits. To be significant at $p<.05$, correlation coefficients must exceed \pm .33 . The male and female pictures yielded intertrait correlations in similar patterns. The traits "honest," "sincere," and "friendly" seemed to form a cluster of covarying ratings for both male and female pictures. For male pictures, "intelligent" was also related to this cluster of traits. In addition, for both male and female pictures, the traits "lazy" and "shy" formed a cluster that was at least somewhat negatively related to most other traits.

Table 3 shows similar correlational data for ratings of typical college students; each correlation is based on 24 pairs of scores. Correlations for typical females are presented in the upper right half and those for typical males in the lower left half of the table. To be significant at $p<.05$, correlation coefficients must exceed \pm .39 . There were fewer substantial correlations among traits describing typical college students than among traits rating actual students in photographs. Both the typical male and the typical female were given ratings for "sincere" that covaried with their ratings for "honest," 
but the other traits clustered with these two for photographic stimuli were not reliably associated with them for typical student ratings. A few other trait pairs correlated substantially for either the typical male ("lazy" and "intelligent," "friendly" and "shy") or the typical female ("friendly" and "intelligent"), but not for both.

\section{DISCUSSION}

The results indicate that males and females form similar impressions about personality characteristics from photographs of people. Whether this similarity extends to impressions of actual people remains to be investigated, but the data for imagined typical students suggest that males and females do maintain similar stereotypes about the personality traits possessed by their peers.

The correlational data relating various personality traits suggest that some of these traits tend to be viewed in clusters, facilitating the operation of the halo effect. A factor analysis could reveal such clustering tendencies, but the present data base was deemed too sparse for meaningful interpretation of such an analysis. However, a casual look at the intercorrelation matrix suggests that there is a cluster of related traits including "honest," "sincere," and "friendly," and for males also including "intelligent," that provides redundant information about impressions formed of people in photographs. When the rated people were imaginary "typical" students, this cluster was less correlated with the trait "friendly." In contrast, the traits "lazy" and "shy" had negative correlations with most other traits for both photographed and imagined stimulus persons, so these traits apparently convey similar information.

Research on individual variations in the disposition to rate persons as high or low on various attributes has recently been reviewed by Kaplan (1976). Evaluating the two major techniques of investigation, Kaplan concluded that the checklist procedure, similar to that used in the present research, yields essentially equivalent results to the more laborious technique of having subjects produce continuous associations, in which the order of appearance of the various responses is used as a measure of their strength. Kaplan also analyzed the relationships that have been investigated between relatively enduring dispositions (traits) and external information available about the persons rated, as codeterminants of the ratings. The data indicate an inverse relationship between the contributions of the dispositional (internal) and the situational (external) determinants of judgments in person perception. That is, internal determinants of trait judgment play a lesser role when external determinants are maximized, as would be the case with photographs as compared to imagined stimulus persons. The present demonstration of strong tendencies for both males and females to cluster personality dimensions, both with and without external information, offers an interesting and potentially important complement to the generalized individual differences demonstrated in previous research.

Many additional interesting features of these data could be explored, but they are beyond the scope of the present paper. We hope that these data provide information of interest to those concerned with personality evaluations of this kind and suggest lines along which research may proceed.

\section{REFERENCES}

Dion, K., Berscheid, E., \& Walster, E. What is beautiful is good. Journal of Personality and Social Psychology, 1972, 24, 285-290.

Kaplan, M. F. Measurement and generality of response dispositions in person perception. Journal of Personality, 1976, 44, 179-194.

Olson, C. L. On choosing a test statistic in multivariate analysis of variance. Psychological Bulletin, 1976, 83, 579-586.

Stone, G. P. Appearance and the self. In A. M. Rose (Ed.), Human behavior and social processes. Boston: Houghton Mifflin, 1962.

ThorNDike, E. L. A constant error in psychological rating. Journal of Applied Psychology, 1920, 4, 25-29.

(Received for publication August 7, 1978.) 